\title{
EXAMINING THE DRIVERS OF AGRIGULTURAL EXPERIMENTATION AMONG SMALLHOLDER FARMERS IN MALAWI
}

\author{
By MICHELE HOCKETT and ROBERT B. RICHARDSON $\dagger$ \\ Department of Community Sustainability, Michigan State University, 480 Wilson Road, \\ East Lansing, MI, 48824-1222, USA
}

(Accepted 11 September 2016; First published online 11 October 2016)

\begin{abstract}
SUMMARY
Smallholder farmers in Malawi are faced with the challenge of managing complex and dynamic farming systems while also adapting to change within volatile agroecological conditions. Moreover, management decisions are influenced by a combination of local knowledge, expert recommendations and on-farm experimentation. Although many smallholder farmers actively experiment with new crops and technologies, little is known about the prevalence of experimentation or the types of experiments farmers conduct. This study examined the decision-making processes of experimenting farmers to explore the drivers of on-farm experimentation. Using a mixed-methods design that incorporated field observations, survey data and in-depth interviews, we identified numerous examples of experiments with new crops, varieties and techniques that had been executed either independently or through participation in an agricultural development project. Results of quantitative and qualitative analysis reveal that smallholder farmers in Malawi across a range of socioeconomic characteristics are inclined to experiment, and gender roles in agricultural experimentation vary widely. While experimental methods differ between farmers, there are commonalities in the drivers of experimentation, including adapting to climate change, improving soil health, improving nutrition and generating income. Smallholders have a great capacity for experimentation, and their knowledge, experience, preferences and priorities - if properly understood and incorporated - could ultimately benefit both future agricultural development projects and their participants.
\end{abstract}

\section{INTRODUGTION}

Approximately $90 \%$ of Malawi's rural population consists of smallholder, subsistence farming households (i.e., producing enough food for consumption, and only enough revenue for immediate needs) who rely on rainfed fields that are less than two hectares on average (IFAD, 2010).

The combination of rising economic inequality, population pressure and the unequal distribution of land has forced smallholders to cultivate smaller parcels of land and reduce or eliminate fallow practices, which has led to the depletion of soil fertility and decreased crop yields. These conditions have especially affected the production of maize, the country's staple food crop, which is often grown continuously and without crop rotations (Bezner Kerr, 2005; Gilbert, 2004). As many rural households in Malawi are dependent on maize, food insecurity is revealed through

${ }^{\dagger}$ Corresponding author. Email: rbr@msu.edu 
high rates of malnutrition, where an estimated $47.1 \%$ of children under 5 years old suffer from growth stunting (UNICEF, 2013). Smallholder agricultural production in Malawi has stagnated due, in part, to rapid population growth and numerous environmental factors and their associated effects on the country's arable land (Bezner Kerr and Patel, 2015; Schulz et al., 2003; Snapp et al., 2010). In efforts to improve agricultural production constraints, many Malawian smallholder farmers are actively experimenting with crop diversification, local methods for weed and disease control, food storage techniques and improved crop varieties as a means to increase food security and generate income at the household level. Unfortunately, little is known about the prevalence of experimentation or the types of experiments farmers conduct. This study examined the decision-making processes of experimenting farmers to explore the drivers of on-farm experimentation.

Case studies from the literature on experimentation provide insight into the innovative capacities of farmers and suggest that farmers are essentially constant experimenters who are continually adapting to the dynamic conditions (e.g., economic, climatic, etc.) upon which their lives and livelihoods depend (Chambers et al., 1989; Scoones and Thompson, 1994; Warren et al., 1995). Farmers have a long history of agricultural experimentation, from potato storage techniques in the Peruvian Andes (Rhoades, 1989) to cocoyam intercropping in northern Ghana (Millar, 1994) to legume varietal selection in Malawi (Ferguson, 1994). However, environmental stressors, emerging technologies and increasing globalization all present new opportunities and risks for smallholder farmers; hence, the literature on agricultural research and development notes the importance of continuing to examine the priorities and capacities of farmers (Scoones and Thompson, 2009). This study contributes to this literature by examining the drivers of decision-making in on-farm experiments with new crops and technologies, particularly among women farmers.

In addition to the on-farm experiments that are conducted by smallholders, development practitioners, researchers, extension officers and other experts are designing and implementing rural development projects that aim to improve agricultural productivity in Malawi. Many such projects have focused on the importance of rotational or intercropping systems - especially with leguminous crops - in tandem with the existing maize-based cropping systems that were born out of colonial-era agricultural policies, and upon which many smallholders are still dependent (Chibwana et al., 2012). The broadening of cropping systems to include legume diversification may contribute to improved soil fertility and household nutrition in Malawi (Bezner Kerr et al., 2007). Legumes have the capacity to grow in marginal ecosystems, and the plants replenish stocks of soil nitrogen and recycle nutrients from the subsoil. The practice of intercropping maize and legumes helps stabilize grain yields, and fertilizer inputs are used more effectively than maize in monocropped systems, thereby enhancing agricultural ecosystem services (Snapp et al., 2010). Legumes can also provide nutritional benefits through much-needed protein and micronutrients such as iron and vitamin A, which are deficient among children throughout many rural regions of Malawi. Legume diversification varies in its role in farming systems, where some farmers are primarily grain producers, 
and others cultivate legume varieties with edible leaves for consumption, proteinrich fodder for livestock or compost to amend the soil (Snapp et al., 2002). Legumes that have been widely promoted in Malawi include common bean (Phaseolus vulgaris), groundnut (Arachis hypogaea), pigeon pea (Cajanus cajan) and soya bean (Glycine max).

Despite the range of agronomic and nutritional benefits, adoption of legume diversification remains low in southern Africa, due in large part to Malawi's Farm Input Subsidy Program (FISP) (Bezner Kerr and Patel, 2015; Chibwana et al., 2012). Farmers who participate in the FISP receive vouchers for hybrid seeds (usually maize and occasionally tobacco) and agricultural inputs at highly subsidized prices, which creates incentives for FISP participants to simplify their farming systems from diversified crop mosaics to monoculture cereal plots. In addition to the FISP, availability and cost of seeds have been identified as barriers to greater cultivation of legumes, along with limited land availability, susceptibility to pests and poor access to markets (Snapp et al., 2002). Those farmers who manage to cultivate the most widely grown legumes are largely motivated by the prospect of home consumption and cash sales (Gilbert, 2004).

Previous research demonstrates that smallholders conduct many different types of experiments and are driven by a variety of goals. Bentley (2006) claims that farmerled experiments are 'motivated by changes in the environment and the economy, and seek to resolve labour and capital constraints' (p. 451). Other studies have classified on-farm experiments into different types, where some farmers experiment out of curiosity, in what has been termed an exploratory experiment (Schön, 1983) or a curiosity experiment (Millar, 1994; Rhoades and Bebbington, 1995). Other farmers innovate to produce a positive change in their farming systems, often in response to conditions that are out of their control (e.g., climate change and variability). This type of experiment has been called a move-testing experiment (Schön, 1983) or a problem-solving experiment (Millar, 1994; Rhoades and Bebbington, 1995). Millar (1994) argues that the most frequent kinds of experiments conducted by farmers are adaptive, whereby a farmer starts with a new technology or technique and reinvents it to suit his or her specific context. Adaptive experiments can also occur when a farmer takes a familiar technique and applies it to a new environment, as in the case of migration (Rhoades and Bebbington, 1995). Bentley (2006) suggests that the best on-farm experiments are adaptive, where farmers do not simply replicate an idea or technique, 'but combine new ideas creatively with local knowledge' (p. 452).

Just as all farmers have different motivations for experimenting (or not), all farmers have different priorities and goals for their farms (Pannell, 1999; Scoones and Thompson, 2009). Among smallholder farmers, who differ little in wealth or education levels given their very small landholdings, the differences in priorities between male and female farmers are striking. Past research has found that while both men and women farmers prefer high-yielding crops (Schulz et al., 2003), women tend to value crops as a food source (such as protein-rich legumes, in particular), while men tend to value crops for their potential to generate income from sale (Bezner Kerr et al., 2007; Bezner Kerr, 2008; Snapp and Silim, 2002). 
After an experiment, a farmer may proceed in one of several ways, depending on her perception of the experiment's success (Sanginga et al., 2009). In the case of a dissatisfactory experiment, the farmer may make adjustments and attempt the experiment again. Alternatively, she may terminate the experiment. In the case of a satisfactory or successful experiment, a farmer may choose to scale-out the innovation and/or repeat it in subsequent seasons. The repeated use of an innovation (which resulted from an experiment) corresponds with the definition of 'individual (farmlevel) adoption', where a new technology is used 'in long-run equilibrium [and] when the farmer has full information about the new technology and its potential' (Feder et al., 1985, p. 256).

Furthermore, Schultz (1975) suggests that experimenting with new technologies will lead a farmer towards equilibrium, where adoption of an innovation is possible. Thus, experimentation is the first step on the adoption spectrum, where experimentation leads to the development of an innovation, and the long-term use of an innovation with repeated successful outcomes will lead to the adoption of that innovation. Such innovations may be adapted or modified by farmers in future experiments, making the process truly iterative (Nitsch, 1990; Sanginga et al., 2009).

There is a significant gap between what is known about conditions for enabling innovation in rural development and what is practiced in mainstream policies. The priorities of smallholders and donor organizations are often poorly aligned, as exemplified by agricultural development projects that promote particular cropping systems or technologies, and are met with low rates of adoption. The result is the promotion of culturally inappropriate technologies that, while potentially beneficial on multiple levels, are not readily adopted by project participants. Low adoption is a major barrier to the diffusion of agricultural innovations (Grabowski et al., 2014). However, culturally appropriate technologies can be developed when farmers' current practices and local knowledge are incorporated into the design and implementation of agricultural interventions in rural development programs (Bentley, 2006; Chambers et al., 1989; Scoones and Thompson, 2009; Sumberg and Okali, 1997). To increase adoption of potentially beneficial recommendations such as legume diversification in smallholder farming systems, agricultural development programs stand to benefit by understanding local agricultural practices, the drivers and motivations of smallholder experimentation and the decision-making processes of farmers regarding new technologies. Special emphasis should be given to the priorities and capacities of women farmers, who play an important role in legume diversification, and who are often neglected in mainstream agricultural development programs (Bezner Kerr and Patel, 2015; Scoones and Thompson, 2009).

The objectives of this study were to examine the decision-making processes of those farmers who were experimenting independently of interventions promoted by rural development projects, draw distinctions between methods used across smallholder experiments and explore the motivations (e.g., attitudes and perceptions) and drivers (e.g., physical and economic resources) of independent experimentation. This study contributes to the literature on smallholder agricultural experimentation by emphasizing the role of experiments in adapting to change, and the role of women 
farmers in experimentation. This paper focussed on the experimentation processes and decision-making of Malawian smallholder farmers, who had tried unfamiliar crops, varieties and/or techniques during the 2012-2013 agricultural season. The study followed a mixed-methods framework and employed a rural household survey, field observations and in-depth interviews to characterize Malawian smallholder farmers, examine experimentation processes and explore on-farm decision-making among smallholders.

\section{MATERIALS AND METHODS}

This study followed a mixed-methods framework that used data collected from field observations, household surveys and in-depth interviews. Quantitative data were collected during the first phase of fieldwork using a household survey, and initial analysis of these data informed both the case selection and the development of interview questions for the second, qualitative phase of fieldwork. The qualitative data were then collected through in-depth interviews with smallholder farmers. A smallholder was defined as a farmer who held less than two hectares of land, meaning that at least $90 \%$ of the farmers in the sample could be identified as smallholders. Descriptive statistics were derived from the survey data and the results from statistical tests informed the analysis of the qualitative interview transcripts, which were thematically coded using NVivo 10 qualitative software. The household survey data provided insight into emergent themes that were explored during qualitative analysis. Likewise, the in-depth interview data helped to contextualize and interpret the findings by bringing distinction to farmers' voices and personal experiences. The integration of methods used in this study yielded a richer understanding of the drivers of on-farm experimentation, the experimental methods used by smallholders and the characteristics of innovative farmers who conduct on-farm experiments.

Fieldwork was conducted in two phases over a 10-week period from mid-May to late-July, 2013. Household surveys were conducted in 22 village clusters across five Extension Planning Areas (EPAs) in two districts of Central Malawi (namely Linthipe, Golomoti, Mtakataka, Kandeu and Nsipe EPAs, in Dedza and Ntcheu Districts). Due to the similarities in agroecological conditions between Golomoti and Mtakataka EPAs, sample populations from these two sites were combined for the purposes of this study. This paper will henceforth refer to this sub-sample simply as Golomoti. Study sites represent range of agro-ecological zones across the four EPAs, and they reflect a variation in terms of market access and agricultural potential. Average elevation ranges from 555 to 1,238 $\mathrm{m}$ above sea level, and annual rainfall varies from approximately 800 to $1,000 \mathrm{~mm}$.

Household lists were obtained from local authorities and a stratified random sampling design was used. The head of household was the targeted respondent within each household. If the household head was unavailable, the survey was administered to another adult household member who had knowledge of the household's agricultural production. This approach yielded survey data characterizing multiple 
household types, including responses from male heads of household, female heads of household and female spouses within male-headed households. Despite the comparative lack of resources and decreased food security experienced by femaleheaded households compared to male-headed households (Bezner Kerr, 2005; Snapp et al., 2002), women are key participants in the Malawian agricultural system. Therefore, in both the surveys and interviews, explicit questions were asked regarding who was responsible for planting experimental crops and how that decision was made, because it cannot be assumed that the head was the only experimenter in any given household.

Household surveys were administered to a sample of 324 farmer participants across the two districts. Survey topics included socioeconomic and demographic characteristics, respondents' perspectives on climatic changes in the region, cropping systems and land use, food security and agricultural production, on-farm experimentation and participation in agricultural development projects. A household was defined as a group of people who live together and share a common kitchen. Regarding gender of the household head, for households where a male lived or worked elsewhere and a female made the household and agricultural decisions more than half of the year, the household was defined as female-headed. If a male was present during the growing season, however, and made most of the agricultural decisions for the household (even if he lived elsewhere before and after the growing season), the household was defined as male-headed. Economically active persons were defined as the age group of 15-69 years old, as persons in rural Malawi are often engaged in agricultural labour until later in life.

Tropical Livestock Units (TLUs) were calculated as indicators of animal (productive) assets across farming system types. The unit is a type of exchange ratio between livestock animals, and is calculated by converting adult body weight into metabolic weight (Jahnke et al., 1988). The Wealth Index was calculated as an assetbased measure of wealth, where both productive and consumer assets, along with housing materials, are assigned numeric values which are added together, and the sum represents the relative wealth of a household.

In addition to socioeconomic and demographic questions, the household survey instrument also contained questions relating to farmers' experimentation practices. Experimentation was defined as any instance where a farmer attempted to use an unfamiliar crop, variety or technique for the first time. Note the temporal difference between a farmer's experimentation with a new technology and her/his adoption of a specific crop, variety or agricultural technique, where adoption is the repeated and unchanging use of a specific crop, variety or agricultural technique over the long term, experimentation is the initial trial of a new or unfamiliar plant or technique - the introduction of a new element into a smallholder's farming system - and is iterative and constantly evolving from season to season. While previous studies have made distinctions between multiple types of experiments in agricultural systems, many smallholder farmers do not readily label their practices as experiments at all. To circumvent this epistemological difference, we used the terminology of 'trying out' an unfamiliar crop, variety or technique for the first time ever to convey questions 
about on-farm experimentation to smallholders who were surveyed and interviewed (Misiko and Tittonell, 2011).

In order to fully understand on-farm experimentation, it is crucial to identify the individual household member who is responsible for conducting an experiment. The survey instrument was used to ask farmers several questions about the distribution of labour during the initial phases of their experiments. A Chi-square test was used to determine the strength of the relationship between the experimenter's gender and the type of experimental crop or variety that was grown. Follow-up questions prompted respondents to give details about the information source for each new crop, variety and technique they reported (e.g., How did you learn about this new crop/variety/technology?). Response categories were derived from three overarching information sources (Sumberg and Okali, 1997):

- Institutions that actively promoted new technologies (e.g., Agricultural Extension Development Officers (AEDOs), development projects of non-profit organizations).

- Peers/others who suggested new technologies or where farmers could observe new technologies (e.g., family member, lead or other farmer, private distributors, social groups, radio).

- Independent ideas of the farmers' own designs.

Immediately following the household survey collection period, a preliminary analysis of the survey data helped provide the basis for the purposive sampling framework that was used in the second, qualitative phase of fieldwork. The sample for the in-depth interviews was drawn from the pool of farmers who had been previously sampled during the household survey phase, and who had reported experimentation with new crops, varieties or technologies, either during the 2012-2013 season or in previous seasons. Additionally, respondents were purposefully drawn from both Dedza and Ntcheu Districts, and represented a range of farm sizes (from 0.2 to $1.82 \mathrm{ha}$ ). In order to better understand farmers' personal ideas of the success or failure of an experiment, the qualitative sample included farmers who had previously reported that their experiments had been successful, along with those who had reported that their experiments had failed. In total, in-depth interviews were held with a sample of 18 farmers (15 females and three males), with ten in Dedza District and eight in Ntcheu District. In the interview sample, women were given greater priority in order to better understand their decision-making processes as related to legume experimentation, given the important role of legumes in soil fertility, food security and household nutrition. This emphasis is reflective both of Malawian women's traditional association with legume crops, and of trends identified in the first phase of this study (surveys), where it was found that females were more likely to experiment with legumes than males.

Interview discussion topics revolved around the following themes: experimentation with unfamiliar crops, varieties and techniques; management of experiments; motivations for trying something new; sources of information; ideas of success and failure; levels of satisfaction with experiments; intentions for future experiments; 
experimentation through agricultural interventions promoted by rural development programs; and general ideas about on-farm experiments (e.g., 'To you, what does it mean to experiment with new crops, varieties, or techniques?'). Most interviews focused on experiments that were carried out in the 2012-2013 agricultural season, although respondents occasionally shared details of experiments that they had conducted prior to 2012 .

The motivations for experimentation as described by farmers in the in-depth interviews were categorized into three types: proactive, reactive and external. Proactive experiments included those that were driven by a farmer's desire to create a positive change in her life circumstances or farm system, for example, to increase food production, generate household income, improve soil fertility or maximize land use. Reactive experiments were those that were prompted by a farmer's response to unexpected circumstances, such as the impacts of climate change, pest or disease problems or access to resources. Lastly, external experiments were those where a farmer was invited to try something new by an influential source (e.g., intervention project or extension agent). Unlike proactive and external motivators that primarily drove new experiments, reactive factors (e.g., climate change, resource availability) could also act as barriers to experimentation.

RESULTS

\section{Respondent characteristics}

Socioeconomic characteristics of the sample by EPA are presented in Table 1. Average household size was 5.1 persons, and the average dependency ratio (number of economically inactive persons divided by number of economically active persons, as shown by number of dependents per 100 persons in the working-age population) was 108 . More than half of household heads completed primary school, but less than $15 \%$ attended secondary school. Regarding average number of fields, farmers did not share a consistent size-based method for breaking sections of land into fields or for breaking fields into plots. In general, however, a piece of land was divided into fields and further sub-divided into plots. Farmers demarcated the land by agroecological factors such as soil type, topography, water holding capacity or cropping systems. Therefore, field and plot level data were gathered based on respondents' definitions of a field or plot on their own farm. No assumptions should be made about the uniformity of field and plot sizes across farms. By farmers' own definitions, it was found that farmers held an average of 2.23 fields. Although the majority of interview respondents represented small households and farms, and scored relatively low on the wealth index, some interview respondents came from large households (seven or more members) and owned numerous reproductive and productive assets (high TLU counts and/or Wealth Index scores). Thus, the interview sample contained representatives from across a wide range of socioeconomic positions within the Malawian smallholder population, which gave insight into the drivers, management practices and decisionmaking processes related to on-farm experimentation across many perspectives. 
Table 1. Demographic characteristics of survey sample, by extension planning area.

\begin{tabular}{lccccc}
\hline & \multicolumn{4}{c}{ EPA } \\
\cline { 2 - 5 } Demographic characteristic & $\begin{array}{c}\text { Linthipe } \\
(\mathrm{n}=83)\end{array}$ & $\begin{array}{c}\text { Golomoti } \\
(\mathrm{n}=80)\end{array}$ & $\begin{array}{c}\text { Kandeu } \\
(\mathrm{n}=81)\end{array}$ & $\begin{array}{c}\text { Nsipe } \\
(\mathrm{n}=80)\end{array}$ & $\begin{array}{c}\text { Total Sample } \\
(\mathrm{n}=324)\end{array}$ \\
\hline \multicolumn{1}{c}{ Male $(n):$} & $57(69 \%)$ & $60(75 \%)$ & $56(69 \%)$ & $58(73 \%)$ & $231(71 \%)$ \\
\multicolumn{1}{c}{ Female $(n):$} & $26(31 \%)$ & $20(25 \%)$ & $25(31 \%)$ & $22(27 \%)$ & $93(29 \%)$ \\
\hline Average household size & 5.20 & 5.10 & 5.20 & 5.10 & 5.10 \\
Average farm size (hectares) & 0.71 & 0.83 & 0.89 & 0.97 & 0.85 \\
Average \# of fields & 2.24 & 1.89 & 2.38 & 2.40 & 2.23 \\
Average Tropical Livestock Units & 0.50 & 0.35 & 0.76 & 0.48 & 0.52 \\
Wealth Index [Range = 2-101] & 15.40 & 15.20 & 16.80 & 17.50 & 16.20 \\
Average \# months food supply & 8.24 & 7.16 & 7.83 & 9.65 & 8.22 \\
Dependency ratio & 112 & 108 & 104 & 108 & 108 \\
\hline
\end{tabular}

\section{Prevalence of experimentation}

Based on farmers' answers to the survey questions, an experimentation classification was created where: Non-experimenters $(\mathrm{n}=96)$ represented farmers who did not report trying anything new in the 2012-2013 season; Project participants ( $\mathrm{n}=$ 145) represented farmers who only reported trying something that had been actively promoted to them (e.g., by extension agents, intervention projects, etc.); Followers $(\mathrm{n}=64)$ represented farmers who reported trying something that they had observed or had heard mention of (e.g., from peers, radio, family members); and Independents $(\mathrm{n}=19)$ represented farmers who reported trying something that was their own idea.

The household survey captured 572 examples of experiments that took place in 2012-2013, where some farmers reported conducting multiple experiments simultaneously. The in-depth interview data, however, reveals that despite the large frequency of experiments reported in the survey, some experiments may have gone unrecorded due to miscommunications and the ways in which farmers conceptualized their own actions. During the in-depth interviews, several farmers interpreted the questions about trying new things to mean trying new things with an intervention project. At the outset of the interviews, some farmers claimed that they had never conducted an experiment prior to joining an intervention project, but by the conclusion of the interview these farmers divulged that they had tried many new things on their own, but they were doing so without thinking of their independent actions as experimental or innovative. Despite the research team's efforts to make the terms experimentation and trying new things mutually understandable on the household survey, it often required an in-depth discussion to surmount the epistemological and linguistic differences between Malawian farmers and researchers. Therefore, although the basic experimentation questions on the survey instrument revealed 572 examples of farmer experiments, it is likely that many more examples were inadvertently omitted. If the assertions are true that farmers are constant experimenters (Chambers et al., 1989; Scoones and Thompson, 1994; Warren et al., 1995) and that on-farm experimentation is 'ubiquitous' (Rhoades and Bebbington, 


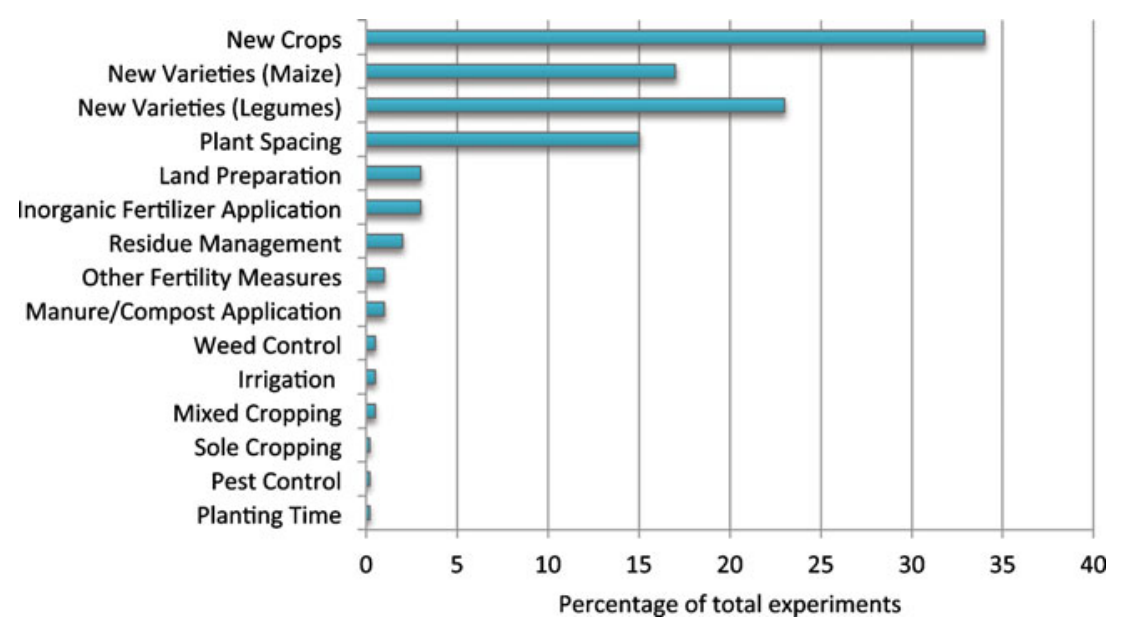

Figure 1. Distribution of experiments by type, frequency (\%).

1995), then it is almost certain that some of the non-experimenters in the survey sample actually were trying new things, but their information was not captured in the fixed-response questionnaire.

\section{Types of experiments}

Of a total of 324 households surveyed, 228 (70.1\%) reported conducting at least one experiment in the 2012-2013 season. Those 228 farmers elicited 572 examples of experimental crops, varieties and/or techniques that they had tried both independently and through an intervention project. The majority of experiments reported on the survey (89\%) fell into three categories: new crops $34 \%$, new varieties (maize and legumes) 40\% and plant spacing experiments 15\% (Figure 1). Similar experiments were grouped together under a common theme (e.g., land preparation experiments include shifting ridges, using box ridges and measuring the precise distance between ridges).

When the experiment examples were disaggregated according to the experimentation classification categories of Project participants, Followers and Independents, similar trends emerged in the frequency distributions (Figure 2a). For reference, (Figure 2b) depicts only the new crop experiments that farmers tried, disaggregated by experimentation classifications. Across all three experimentation classifications, farmers had a propensity to try new crops, varieties and plant spacing techniques more often than other types of experiments. Note that a larger percentage of Independent experimenters (18\%) and Followers $(25 \%)$ tried new maize varieties than did Project participants (14\%). Additionally, Project participants tried more new leguminous varieties than either Independent experimenters or Followers $(26 \%$ compared to $14 \%$ and $16 \%$, respectively) (Figure 2a). Likewise, a much greater percentage of Project participants tried pigeon pea $(60 \%)$ than either Independent experimenters $(30 \%)$ or Followers $(33 \%)$ (Figure $2 \mathrm{~b}$ ). These trends are reflective of 

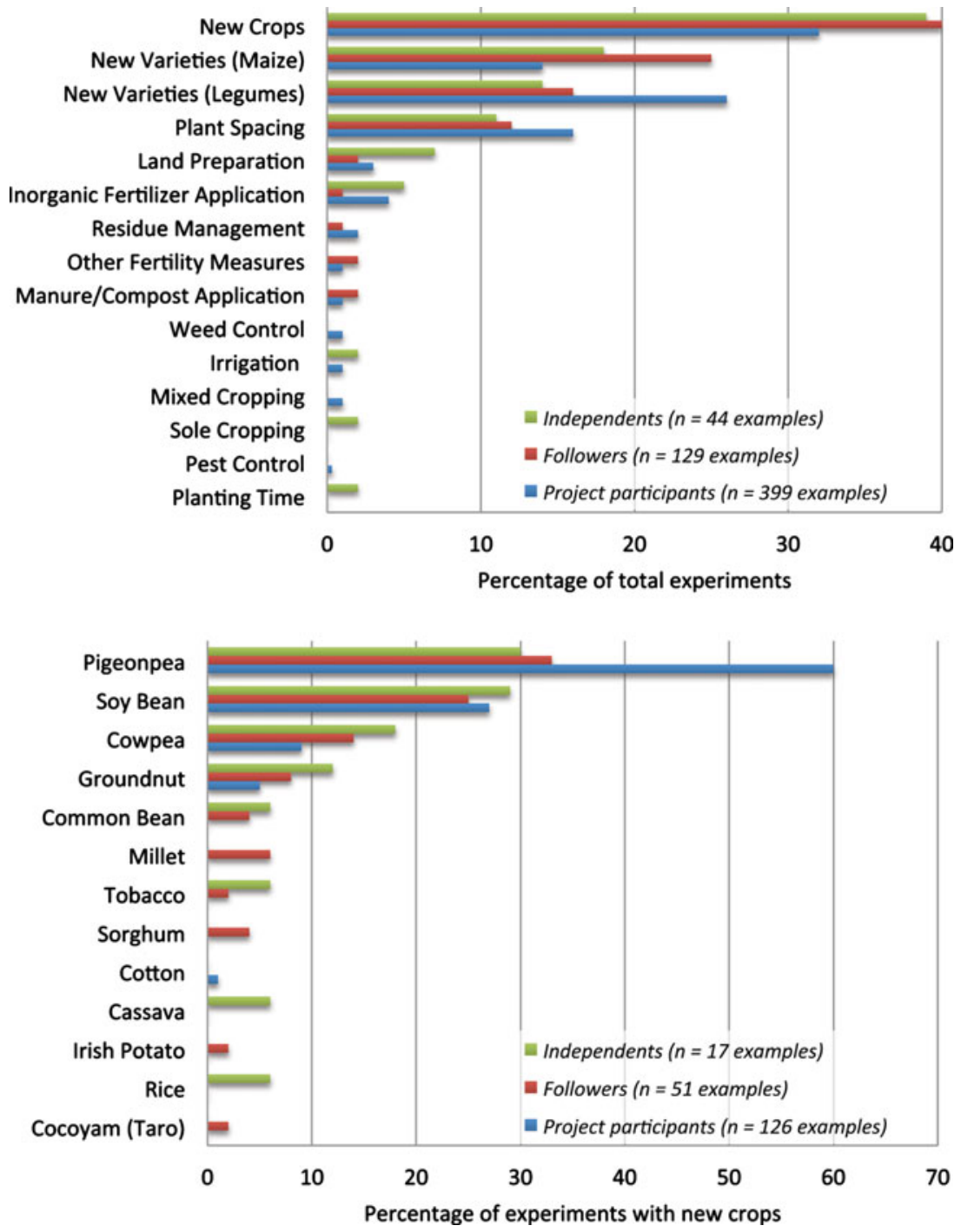

Figure 2. (a) Distribution of experiments by experimenter group (\%). (b) Distribution of experiments with new crops by experimenter group (\%).

recommendations made by several agricultural development organizations that were working in the study area during the 2012-2013 season. Leguminous crops such as pigeon pea were actively promoted by these organizations due to the potential of these crops to increase soil fertility and household nutrition in central Malawi.

Although some agricultural intervention projects in the study area promoted the growth of specific legume crops, the popularity of legumes among farmer innovators should not be dismissed as a byproduct of these programs. Of the experimental crops that farmers had tried in 2012-2013,94\% were leguminous, and of the experimental varieties that farmers had tried in 2012-2013, 57.1\% were leguminous. In addition 
Table 2. Examples of farmers' experiments from interviews.

\begin{tabular}{|c|c|}
\hline Type of Experiment & Quotations from Interviews \\
\hline New Variety & $\begin{array}{l}\text { 2134: For groundnuts, I tried a new variety... Because we were told that this new } \\
\text { variety of groundnuts yields more than the local variety. }\end{array}$ \\
\hline New Crop & 3205: The new crop I've tried is pigeonpea that we received. \\
\hline $\begin{array}{l}\text { Plant Spacing + } \\
\text { Land Preparation }\end{array}$ & $\begin{array}{l}\text { 1217: We take a ruler then we use it to make sure the distance between planting } \\
\text { stations is the same, and also the distance between the ridges is the same. Then we } \\
\text { use a small plot and apply manure on that plot. Then we plant the seed using } 1: 1 \\
\text { technique*. Then we see the difference from where we were planting } 3: 3 \text {. We like } \\
\text { to see the difference. }\end{array}$ \\
\hline $\begin{array}{l}\text { Land Preparation }+ \\
\text { Residue }\end{array}$ & $\begin{array}{l}\text { 4219: With the fertility of our soils, now we've started incorporating residues and } \\
\text { we've starting using box ridges so that when there is a lot of rain, we don't lose the }\end{array}$ \\
\hline Management & $\begin{array}{l}\text { water. Rather the box ridges should hold some of the water so in case of drought, } \\
\text { the crops will survive. And also, incorporating crop residues traps the moisture in } \\
\text { the soil. So then, when there is a lot of sun the crops don't die. Then, we plant the } \\
\text { crops we want on the fields. }\end{array}$ \\
\hline Sole Cropping & $\begin{array}{l}\text { 3205: ... because previously we were just intercropping, in the same field maize, in } \\
\text { the same field soya, and in the same field groundnuts. So last season was the first } \\
\text { time to divide the field into 3: on one plot soya, on another plot maize, on the last } \\
\text { plot groundnuts. }\end{array}$ \\
\hline
\end{tabular}

\footnotetext{
*A specific plant and seed spacing for maize, where one seed is planted per planting station, and one planting station is placed per foot.
}

to the descriptive statistics, the in-depth farmer interviews provide insight into the types of experiments farmers were trying. The quotations provided in Table 2 are representative of the experimentation themes that were created based on survey and interview responses, and demonstrate the wide variety of experiments that farmers were conducting during the 2012-2013 season (responses are marked with household identification numbers).

\section{Gender, experimentation and household decision-making}

The Chi-square tests revealed that the experimenter's gender did not have a statistically significant effect on the types of crops/varieties that were planted experimentally, or on the type of experimental technique that was attempted (Crops: $\chi 2(9, \mathrm{n}=194)=7.37, p>0.05$; Varieties: $\chi 2(3, \mathrm{n}=226)=0.81, p>0.05$; Technologies: $\chi 2(22, \mathrm{n}=152)=31.21, p>0.05$. Despite the non-significant $p$-value of the Chi-square test, there are several important trends that emerged in the analysis (Table 3). Most experimental legume crops and varieties grown in the 2012-2013 season were planted and managed by both spouses together $(45.6 \%$ of experiments with new crops were planted by both spouses; $55 \%$ of experiments with new varieties were planted and managed by both spouses). In instances where only one person reported planting an experimental legume crop, however, women planted over twice as many unfamiliar legume crops as men (36.3\% compared to $17.6 \%$ planted by men). Similarly, women planted over four times as many experimental legume varieties as men $(35.7 \%$ by women compared to $8.5 \%$ by men). In general, experiments with crops, varieties and technologies that were conducted by only one person were twice as likely to be led by individual women as men. 
Table 3. Types of experiments, by gender.

\begin{tabular}{lccccr}
\hline Type of Experiment & Male & Female & Both & Other* & Total \\
\hline Crops & & & & & \\
Legumes & $32(17.6 \%)$ & $66(36.3 \%)$ & $83(45.6 \%)$ & $1(0.5 \%)$ & 182 \\
Cash & $1(33.3 \%)$ & 0 & $2(66.7 \%)$ & 0 & 3 \\
Tubers & $2(66.7 \%)$ & 0 & $1(33.3 \%)$ & 0 & 3 \\
Grains & $1(16.7 \%)$ & $3(50 \%)$ & $2(33.3 \%)$ & 0 & 6 \\
Total & $36(18.6 \%)$ & $69(35.6 \%)$ & $88(45.4 \%)$ & $1(0.5 \%)$ & 194 \\
Varieties & $6(6.2 \%)$ & $39(40.2 \%)$ & $51(52.6 \%)$ & $1(1 \%)$ & 97 \\
Maize & $11(8.5 \%)$ & $46(35.7 \%)$ & $71(55 \%)$ & $1(0.8 \%)$ & 129 \\
Legumes & $17(7.5 \%)$ & $85(37.6 \%)$ & $122(54 \%)$ & $2(0.9 \%)$ & 226 \\
Total & $22(14.5 \%)$ & $48(31.6 \%)$ & $82(53.9 \%)$ & 0 & 152 \\
Techniques & $75(13.1 \%)$ & $202(35.3 \%)$ & $292(51.0 \%)$ & $3(0.5 \%)$ & 572 \\
Total & Total Experiments & & & & \\
\hline
\end{tabular}

*Represents laborer for whom no gender information was known (e.g., child).

\section{Motivations and decision-making processes}

During the in-depth interviews, farmers spoke of proactive experimentation 162 times, reactive experimentation 65 times and external experiments 77 times. It was not uncommon, however, for farmers to attribute experimentation to a combination of motivators. Table 4 draws upon farmer quotes to provide examples of experiments in all three motivation categories, as well as experiments that were driven by multiple motivations.

During the interview process, farmers explained that their experiments with maize varieties were driven by reaction to changes in rainfall patterns more than any other motivator. These findings are compounded when compared with the survey data, where $86.1 \%$ of farmers said they had noticed changes in the rains over the last 20 years, and out of those farmers, $67.2 \%$ reported that the changes they noticed included less rain, erratic rainfall and a tendency for the rains to stop before the crops had matured. These results indicate that farmers are not only noticing the effects of climate change, but they are actively experimenting with maize varieties and new techniques in an effort to adapt to undesirable environmental changes. In addition to climate change, farmers cited their landholdings (or the number of fields held by a farmer) as a factor that affected their decision-making processes during an experiment. Many farmers shared the opinion that initiating a new experiment - or scaling out a successful experiment - required extra space, which often meant renting additional land.

\section{Perceptions of success and failure}

At the conclusion of an experiment, farmers undergo a decision-making process to determine whether they will repeat, adjust and repeat (i.e., scale out, scale back or make a change), or abandon their original experiment. Regarding farmers' assessment criteria, interview respondents defined an experiment as a success if 
Table 4. Farmers' motivations for experimentation.

\begin{tabular}{|c|c|}
\hline Motivation & Examples from Interviews \\
\hline Proactive & $\begin{array}{l}\text { 1105: I tried this because there wasn't enough food for my household. I have small children } \\
\text { who are orphans, so if I don't work hard, I'll have problems with raising the kids. } \\
\text { 2301: I like to be like these other people who do not lack things. We should not just rely on } \\
\text { getting help from other people, but we should be self reliant. That's why we experiment. } \\
\text { 4129: For soya, most people who grow it can sell it and get lots of money. When you harvest a } \\
\text { lot, you can sell it and use the money for other household needs. }\end{array}$ \\
\hline Reactive & $\begin{array}{l}\text { 1140: We try new things because of the changes in the rain. That's why we stopped planting } \\
\text { those crops which are hard to grow when the rains aren't enough, and go instead for those } \\
\text { crops which still grow well with less rain. } \\
\text { 4134: I would try something [new] if I had enough resources. But the main problem here is } \\
\text { fertilizer, because the prices of fertilizer have risen very high. But if we had enough fertilizer, } \\
\text { we could experiment. } \\
\text { 4219: We weren't happy with the prices for which we sold the cotton. That's why this year we } \\
\text { only grew tobacco. }\end{array}$ \\
\hline External & $\begin{array}{l}\text { 2263: Experimenting, sometimes the AEDO tells us to do it like this, like this, like this. Then } \\
\text { we go to our fields and practice what he advised us. } \\
\text { 3105: The AEDO told us that there's also pigeonpea here, and you need to plant it. We didn't } \\
\text { refuse that. We received the seed just to try it. } \\
\text { 4110: We received it from [an agricultural intervention project], so I wanted to see its yields. }\end{array}$ \\
\hline $\begin{array}{l}\text { Multiple } \\
\text { Motivations }\end{array}$ & $\begin{array}{l}\text { 2134: For us to grow soya, they told us that we may get two main benefits. One is making soya } \\
\text { porridge from soya flour, and the other is getting money from the sales. So when we } \\
\text { received the soya seed, we decided to grow it to make soya porridge for the children, and } \\
\text { it's nutritious. And the remaining produce, to sell. [External, proactive] } \\
\text { 3126: Because of the problems with the local varieties. We wanted to compare the new } \\
\text { varieties and the old varieties to see which one will yield more, and which one would } \\
\text { benefit us the most. [Reactive, proactive] } \\
\text { 4219: Because when we were conducting our tobacco meetings, we were told that a farmer } \\
\text { shouldn't just rely on one crop. For example, if you grow maize and you rely on it to eat and } \\
\text { to sell, it won't work well. You need to grow more than one crop, so that if one crop isn't } \\
\text { selling well, you can try the other crop. And also, if you rely on one crop, when the rains } \\
\text { aren't good you'll suffer a lot because you won't have food for your household. [External, } \\
\text { proactive] }\end{array}$ \\
\hline
\end{tabular}

the experimenter gained something from it, such as food, income, knowledge, etc. Quotations that illustrate farmers' perspectives on success and failure are presented below (interviewer questions are marked as 'INT', and responses are marked with household identifications numbers):

4104: I saw that the maize yielded well, unlike just planting without using anything. Planting without anything, you get nothing. But planting with manure, at least you get something.

INT: So do you think that this was a successful experiment that you tried? 4104: Yes, it's a good technique because if you don't have enough money to buy fertilizer, you can just use manure.

INT: So do you think that that new spacing was a successful experiment...? 4110: Yes. 
INT: And why do you think so?

4110: Because previously, we were just planting plants one here, the other one over there [with larger spaces between plants], without following any strategy. Instead of planting many seeds in a row, we were only planting a few seeds per row. Where before we were planting 3 seeds, now we're planting 6, and now we're harvesting more.

Farmers described a failed experiment as one that did not meet their expectations or desired outcomes:

1105: It has proved to be a failure because I've tried it twice [without harvesting anything].

3205: For the pigeon pea, we just planted it, and now the goats are eating it. So we haven't seen any benefits from it.

Farmers consistently associated successful experiments with feelings of happiness or satisfaction, but they did not always equate failed experiments with dissatisfaction. On the contrary, it was common for an innovator to be satisfied with the outcomes of a failed experiment if they felt that they had learned something in the process, or that the experiment's failure could be attributed to another factor beyond the experimental crop or technique, itself (e.g., weather, personal health, etc.):

3126: No. Since the beginning we got nothing.

INT: So are you happy that you tried that this year?

3126: Very much!

INT: Why?!

3126: This just happened because of the rains.

INT: Were you happy that you planted it?

4129: Yes.

INT: Why were you happy, even though you had no yield?

4129: Because I tried to grow it, just the way my friends did. It didn't work well because I was in the hospital.

The relationship between a farmer's ideas of success (failure), satisfaction (dissatisfaction) and future intentions for an experiment is not direct, but is mediated by other factors. Thus, dissatisfaction with an experiment does not necessarily result in the abandonment of that experiment. Likewise, satisfaction with an experiment does not necessarily result in its repetition, as repetition is somewhat dependent on a farmer's access to resources such as follows: landholdings (both total farm size and number of fields); input availability in local markets, from intervention projects or through government subsidies (e.g., seed, fertilizer, pesticides, etc.); household income to purchase agricultural inputs; and available labour (which is closely related to a farmer's personal health). Overall, farmers expressed that their choice to continue or abandon an experiment varies from season to season, depending on a host of external factors. This sentiment is consistent with the theoretical frameworks supporting this 
study (Nitsch, 1990; Schön, 1983), where experimentation is defined as an iterative and context-specific phenomenon.

\section{DISCUSSION}

On-farm experiments are deliberately planned and executed by tenacious smallholders whose decisions are influenced by internal preferences and external factors. Farmer-led experiments, however, differ from formal research experiments in structure, purpose, validity and criteria for success (Bentley, 2006; Misiko and Tittonell, 2011; Rhoades, 1989; Rhoades and Bebbington, 1995; Schön, 1983; Scoones and Thompson, 1994; Scoones and Thompson, 2009). On-farm experiments can be likened to a musical performance (Richards, 1989); while scientific researchers (and composers) strive for precision and control in their work, farmers must experiment in dynamic and unstable environments, just as musicians must deal with bad acoustics, stage fright and other uncontrollable factors when performing a composition. During on-farm experimentation, smallholders must adapt to changing climatic conditions, variable markets, limited resources and a host of other challenges for which researchers in controlled settings may not need to compensate. Thus, while on-farm experiments often do not employ the precision of the scientific method (Bentley, 2006), these experiments are essential, carefully planned and often result in meaningful innovations.

Similarly, while replicability and generalizability are necessary measures that validate scientific experiments, these measures are often neither necessary nor possible in on-farm experiments. Farmers may not have the capacity for replication due to ever-changing and restrictive factors such as weather, land constraints and resource availability. On-farm experiments are not constructed to be generalizable across a wide range of contexts, but rather they are crafted to fit the conditions of a specific farming system. Where formal experiments can be repeated under controlled circumstances, farmer-led experiments are the 'real practice' (Misiko and Tittonell, 2011, p. 1137).

Scientific researchers and smallholder farmers also use different criteria to judge the success of an experiment. Scientists and researchers in the formal sector may define a successful experiment by the rejection of a null hypothesis or a high level of statistical significance (Schön, 1983). Smallholders, however, may deem an experiment successful if it can help them adapt to their circumstances and make it through to the next season, if it can survive or thrive over the long-term, if it results in a pleasing outcome (Misiko and Tittonell, 2011; Rhoades and Bebbington, 1995; Scoones and Thompson, 1994), or if it 'leads to the discovery of something there' (Schön, 1983, p. 145). For smallholders, there is a wide range of criteria that distinguishes a successful experiment from a failure.

While experimentation is not ubiquitous among smallholder households in Malawi, it is widespread, especially considering that many examples of experimentation may have been inadvertently omitted due to the epistemological and linguistic differences between smallholders and researchers. Overall, farmers reported that the 
vast majority of their experiments in 2012-2013 fell into three categories: (i) new crops, (ii) new varieties (maize and non-maize) and (iii) plant spacing experiments. When experiment examples were disaggregated according to the experimentation classification categories of Participants, Followers and Independents, similar trends emerged: Within all three groups, experimenting farmers had a propensity to try new crops, varieties and plant spacing techniques more often than other types of experiments. Additionally, the study found that the majority of the experimental crops and more than half of the experimental varieties that farmers had tried in 2012-2013 involved legumes. These data illustrate that regardless of the source of an experimenter's ideas, smallholders had specific interest in experimenting with leguminous crops and varieties primarily, and with maize varieties secondarily. These findings have implications for understanding the role of women farmers in experimentation with legumes, which is an important contribution of this study to the literature on smallholder agricultural experimentation.

Most crop and varietal experiments were driven primarily by proactive and external influences such as income generation or participation in an intervention project. This is to be expected, as approximately $44.7 \%$ of survey respondents indicated that they were participants in a rural development project. Many farmers reported experimentation with legume crops in order to meet an array of diverse goals, including finding viable cash crop alternatives to cotton or tobacco; achieving nutritional benefits of legumes and their positive influence on child development; and enhancing soil fertility in degraded environments. Farmers who experimented with legumes were motivated by a wide range of priorities and concerns, and experimenting farmers expressed interest in trying new legume crops or varieties if they thought the legumes would meet multiple goals.

The apparent preference among experimenting farmers to try new leguminous crops and varieties is in line with literature that illustrates the high potential of legumes to meet multiple objectives and household needs (Millar, 1994; Rhoades and Bebbington, 1995). Depending on the crops and systems that are implemented (e.g., intercrops or seasonal rotations), maize-legume cropping systems have the potential to yield benefits such as improved soil fertility from nitrogen fixation, reduced pest and disease pressures, improved soil organic matter and water infiltration (through the incorporation of crop residues), use as fodder for livestock, income generation (e.g., groundnut, which can be sold in markets), lower seed costs, lower labour requirements, later maturity (available when other food sources are not), higher provision of calories and protein (relative to a maize-based diet) and secondary use as medicine (Gilbert, 2004; Snapp and Silim, 2002).

One of the most highly valued benefits of legumes is their high protein and caloric content, a trait that is especially prized by female farmers who are responsible for feeding children. This may explain why legume experiments were so common among women farmers in the sample population, since women were involved (either with their spouses or alone) in $81.9 \%$ of experiments involving new legume crops, and $90.7 \%$ of experiments involving new legume varieties. It seems that agricultural experimentation has provided women with a unique opportunity to meet 
household objectives that they deem critically important such as enhancing children's nutrition. This finding represents an important contribution to an understanding of the priorities and capacities of women farmers, who play a significant role in legume diversification, and who are often neglected in agricultural extension and development programs (Bezner Kerr and Patel, 2015; Scoones and Thompson, 2009). Despite the traditional matrilineal landholding system and inheritance practices among the Chewa people of Malawi (Berge et al., 2014), this study found that agricultural gender roles were not split between fields (e.g., men's fields and women's fields), but rather between the particular crops on a field. For example, men's crops included cash commodities such as tobacco and cotton, whereas women typically cultivated food crops such as maize and legumes. This study did not, therefore, find any differences in experimentation according to lineage-based landholding system.

Despite the myriad benefits of leguminous crops, maize is widely regarded as the most important crop for Malawian subsistence farmers (IFAD, 2010), which underscores the sentiment of many experimenters who expressed that their main motivation for maize experimentation was maintaining yields of this staple crop in the face of climate change (a reactive motivation). The majority of farmers $(86.1 \%)$ in the household survey sample reported noticing rainfall changes in the past 20 years, and many farmers expressed concern about how their livelihoods would be impacted by those changes. These concerned farmers actively experimented with maize varieties (and new techniques, in some instances) in an effort to mitigate the undesirable effects of climate change. These findings demonstrate that farmers are motived by specific objectives in accordance with contextual concerns and goals. Before promoting a certain crop or variety in a given area, agricultural development programs should consider the knowledge, priorities and concerns of local farmers.

Most farmers described feeling satisfied with the outcomes of an experiment, regardless of whether they saw the experiment as a success or a failure. Likewise, many farmers only expressed dissatisfaction with an experiment if they felt they had gained absolutely nothing from it (e.g., knowledge, higher yields, income). Depending on the interplay between farmers' assessment of the performance of their experiments, their satisfaction with the experiment and their available resources, farmers will make the decision whether to repeat, adjust and repeat, or abandon an experiment. In addition, women were found to be key experimenters, especially regarding legume experimentation. Women were involved in more than $80 \%$ of experiments involving new legume crops, and more than 90\% of experiments involving new legume varieties, and female respondents expressed their desire to experiment with crops and varieties that would meet multiple goals. During an intervention program, then, it is critical to examine the priorities and capacities of women farmers during the baseline data collection period, especially if the intervention involves leguminous crops.

\section{Limitations and implications for future research}

Although this study provided insight into smallholder experimentation in Malawi, there were limitations to the framework employed, and there are questions about 
farmer experiments that are yet unanswered. Many respondents were asked to detail experiments from several months or years prior to the interviews, and therefore recall error may have resulted in the omission of some cases of experimentation from the study. Epistemological and linguistic differences between farmers and researchers may have also contributed to miscommunication. To circumvent similar issues in future studies, in-depth interviews could be conducted with selfidentified non-experimenters to understand whether these farmers were really not trying new things, or if they were experimenting but failed to report their attempts due to some misunderstanding. In this study, the perspectives of nonexperimenters may have provided some insight into the barriers or challenges associated with on-farm experimentation. Future experimentation studies might also implement a mixed-methods longitudinal design that begins by recording farmers' intentions before planting (i.e., their hopes and goals for experiments), measures the success of and modifications to those experiments throughout the growing season, documents the post-harvest outcomes and records farmers' modifications to their experimental designs in the following season. Such studies would provide a comprehensive depiction of on-farm experimentation, and would reduce recall error and miscommunication between researchers and farmers. Finally, over the course of this study, it became clear that farmers in central Malawi are regularly inundated with new ideas from numerous sources, including messages from agricultural extension officers, radio programs, seed distributors, subsidy programs, development programs and peers, to name only a few. Due to this saturation of new ideas in the region, it was difficult to measure truly independent experimentation. Previous studies have found that farmers worldwide are actively experimenting, but farmers in less densely populated areas may be trying crops, varieties and techniques differently. By conducting similar studies across the world, knowledge about on-farm experimentation and innovation can potentially contribute to global food security.

\section{CONCLUSION}

The findings of this study offer validation of the experimentation processes of innovative smallholders to the research, extension and development communities. It contributes to the literature on smallholder agricultural experimentation by emphasizing the role of adaptation to change, and the role of women farmers in experimentation. Malawian farmers are trying new approaches in conjunction with experts, but they are also bolstering their own expertise by experimenting independently. It is clear that smallholders have a great capacity for experimentation, and their knowledge, experience, preferences and priorities - if properly understood and incorporated - could ultimately benefit both future agricultural development projects and their participants. Information about the technologies smallholders are trying, the rationale for trying new things and the characteristics of experimenting farmers within households provide useful knowledge about the decision-making processes and priorities of Malawian farmers. Future rural development projects that consider these decision-making processes and reflect farmers' knowledge and 
priorities are likely to result in more relevant, readily adopted technologies for improving agricultural productivity in Malawi.

Acknowledgements. This study benefitted from contributions and insights from Dr Sieglinde Snapp, Dr Regis Chikowo and Mr. Alex Smith. The research was made possible with support from the United States Agency for International Development (USAID) through the Africa Research in Sustainable Intensification for the Next Generation (Africa RISING) program as part of the US Government's Feed the Future Initiative. Any errors or omissions are those of the authors.

\section{REFERENCES}

Bentley, J. W. (2006). Folk experiments. Agriculture and Human Values 23(4):451-462.

Berge, E., Kambewa, D. Munthali, A. and Wiig, H. (2014). Lineage and land reforms in Malawi: Do matrilineal and patrilineal landholding systems represent a problem for land reforms in Malawi? Land Use Policy 41:61-69.

Bezner Kerr, R. (2005). Food security in northern Malawi: Gender, kinship relations and entitlements in historical context. Fournal of Southern African Studies 31(1):53-74.

Bezner Kerr, R. (2008). Gender and agrarian inequality at the local scale. In Agricultural Systems: Agroecology and Rural Innovation for Development, 279-306 (Eds S. S. Snapp and B. Pound). London: Academic Press.

Bezner Kerr, R. and Patel, R. (2015). Food security in Malawi: Disputed diagnoses, different prescriptions. In Food Security and Development: Country Cases, 205-229. (Ed N. Sekhar). London: Earthscan/Routledge.

Bezner Kerr, R., Snapp, S., Chirwa, M., Shumba, L. and Msachi, R. (2007). Participatory research on legume diversification with Malawian smallholder farmers for improved human nutrition and soil fertility. Experimental Agriculture 43(4):437-453.

Chambers, R., Pacey, A. and Thrupp, L. A. (Eds.) (1989). Farmer First: Farmer Innovation and Agricultural Research. London: Intermediate Technology Publications.

Chibwana, G., Fisher, M. and Shively, G. (2012). Cropland allocation effects of agricultural input subsidies in Malawi. World Development 40(1):124-133.

Feder, G., Just, R. E. and Zilberman, D. (1985). Adoption of agricultural innovations in developing countries: A survey. Economic Development and Cultural Change 33(2):255-298.

Ferguson, A. E. (1994). Gendered science: A critique of agricultural development. American Anthropologist 96:540-552.

Gilbert, R. A. (2004). Best-bet legumes for smallholder maize-based cropping systems of Malawi. In Green Manure/Cover Crop Systems of Smallholder Farmers: Experiences from Tropical and Subtropical Regions, 153-174 (Eds M. Eilittä, J. Mureithi and R. Derpsch). Dordrecht: Kluwer Academic Publishers.

Grabowski, P. P., Haggblade, S. Kabwe, S. and Tembo, G. (2014). Minimum tillage adoption among commercial smallholder cotton farmers in Zambia, 2002 to 2011. Agricultural Systems 131:34-44.

IFAD (International Fund for Agricultural Development). (2010). Rural poverty in Malawi. Retrieved from http: //www.ruralpovertyportal.org/country/home/tags/malawi.

Jahnke, H. E., Tacher, G., Kiel, P. and Rojat, D. (1988). Livestock production in tropical Africa, with special reference to the tsetse-affected zone. In Livestock Production in Tsetse-Affected Areas of Africa, 3-21. Proceedings of a Meeting Held in Nairobi, 23-27 November 1987. Nairobi, Kenya: International Livestock Centre for Africa and the International Laboratory for Research on Animal Diseases.

Millar, D. (1994). Experimenting farmers in northern Ghana. In Beyond Farmer First: Rural People's Knoweledge, Agricultural Research and Extension Practice, 160-165 (Eds I. Scoones and J. Thompson). London: Intermediate Technology Publications.

Misiko, M. and Tittonell, P. (2011). Counting eggs? Smallholder experiments and tryouts as success indicators of adoption of soil fertility technologies. In Innovations as Key to the Green Revolution in Africa: Exploring the Scientific Facts, 1137-1144 (Eds A. Bationo, B. Waswa, J. M. Okeyo, F. Maina and J. M. Kihara). Dordrecht: Springer Science+Business Media B.V.

Nitsch, U. (1990). Computers and the nature of farm management. Knowledge, Technology and Policy 3(3):67-75.

Pannell, D. J. (1999). Economics, extension and the adoption of land conservation innovations in agriculture. International Fournal of Social Economics 26(7/8/9):999-1014. 
Rhoades, R. (1989). The role of farmers in the creation of agricultural technology. In Farmer First: Farmer Innovation and Agricultural Research, 3-9 (Eds R. Chambers, A. Pacey and L. A. Thrupp). London: Intermediate Technology Publications.

Rhoades, R. and Bebbington, A. (1995). Farmers who experiment: An untapped resource for agricultural research and development. In The Cultural Dimension of Development: Indigenous Knowledge Systems, 296-307 (Eds D. M. Warren, L. J. Slikkerveer and D. Brokensha). London: Intermediate Technology Publications.

Richards, P. (1989). Agriculture as a performance. In Farmer First: Farmer Innovation and Agricultural Research, 39-43 (Eds R. Chambers, A. Pacey and L. A. Thrupp). London: Intermediate Technology Publications.

Sanginga, P. C., Waters-Bayer, A., Kaaria, S., Njuki, J. and Wettasinha, C. (2009). Innovations Africa: Beyond rhetoric to praxis. In Innovation Africa: Enriching Farmers' Livelihoods, 374-386 (Eds P. C. Sanginga, A. Waters-Bayer, S. Kaaria, J. Njuki and C. Wettasinha). London, CT: Earthscan.

Schön, D. A. (1983). The Reflective Practitioner: How Professionals Think in Action. New York: Basic Books.

Schultz, T. W. (1975). The value of the ability to deal with disequilibria. Fournal of Economic Literature 13(3):827-846.

Schulz, S., Honlonkou, A. N., Carsky, R. J., Manyong, V. M. and Oyewole, B. D. (2003). Alternatives to Mucuna for soil fertility management in southern Benin: Farmer perception and use of traditional and exotic grain legumes. Experimental Agriculture 39(3):267-278.

Scoones, I. and Thompson, J. (1994). Knowledge, power and agriculture-towards a theoretical understanding. In Beyond Farmer First: Rural People's Knowledge, Agricultural Research and Extension Practice, 16-32 (Eds I. Scoones and J. Thompson). London: Intermediate Technology Publications.

Scoones, I. and Thompson, J. (2009). Farmer First revisited: Innovation for agricultural research and development. In Farmer First Revisited: Innovation for Agricultural Research and Development, 3-30 (Eds I. Scoones and J. Thompson). Warwickshire, UK: Practical Action Publishing.

Snapp, S., Kanyama-Phiri, G., Kamanga, B., Gilbert, R. and Wellard, K. (2002). Farmer and researcher partnerships in Malawi: Developing soil fertility technologies for the near-term and far-term. Experimental Agriculture 38(4):411431.

Snapp, S. S. and Silim, S. N. (2002). Farmer preferences and legume intensification for low nutrient environments. Plant and Soil 245:181-192.

Snapp, S. S., Blackie, M. J., Gilbert, R. A., Bezner Kerr, R. and Kanyama-Phiri, G. Y. (2010). Biodiversity can support a greener revolution in Africa. Proceedings of the National Academy of Sciences 107(48):20840-20845.

Sumberg, J. E. and Okali, C. (1997). Farmers' Experiments: Creating Local Knowledge. Boulder: Lynne Rienner.

Warren, M. D., Slikkerveer, L. J. and Brokensha, D. (Eds.) (1995). The Cultural Dimension of Development: Indigenous Knowledge Systems. London: Intermediate Technology Publications.

UNICEF (United Nations Children's Fund). (2013). Malawi. Retrieved from http://www.unicef.org/infobycountry/ malawi_statistics.html. 